\title{
Tinjauan Sistem Informasi Pendaftaran Pasien Rawat Jalan di RSUD Tebet Jakarta Selatan
}

\section{Overview of the Outpatient Registration Information System at Tebet Hospital, South Jakarta}

\author{
Rabnah $^{1}$, Adi Widodo ${ }^{2}$, Daniel Happy Putra ${ }^{3}$, Noor Yulia ${ }^{4}$ \\ 1,2,3,4 Universitas Esa Unggul \\ Jl. Arjuna Utara No.9, Kb. Jeruk, Kec. Kb. Jeruk, Kota Jakarta Barat, Daerah Khusus Ibukota Jakarta \\ 11510 \\ *e-mail korespondensi: rabnahseff31@gmail.com
}

\begin{abstract}
Abstrak
Pendaftaran pasien rawat jalan merupakan pelayanan awal yang diberikan oleh Rumah Sakit kepada pasien. Pendaftaran pasien rawat jalan di RSUD Tebet Jakarta sudah terkomputerisasi dengan berbasis website. Tujuan umum dari penelitian ini adalah meninjau sistem informasi yang ada di pendaftaran tersebut dapat terminimalisir. Metode penelitian yang dilakukan dengan metode deskriptif bersifat analisa kualitatif. Teknik pengumpulandata dengan cara observasi dan wawancara. Dari hasil penelitian, RSUD Tebet Jakarta sudah melakukan pendaftaran pasien secara komputerisasi berbasis website, dengan menggunakan aplikasi yang bernama Hospital Information System (HIS) yang dibuat oleh RSUD Tebet Jakarta dan bekerja sama dengan vendor. Aplikasi Hospital Information System (HIS) tersebut masih terdapat kendala-kendala yang sering muncul diantaranya adalah untuk pencarian data pasien lama yang tidak membawa kartu berobat yang dilakukan telah sesuai dengan aturan Rekam Medis yaitu hanya memasukkan tanggal lahir pasien namun di RSUD Tebet masih terdapat duplikasi data pasien saat dilakukan pencarian data pasien berdasarkan tanggal lahir dikarenakan didalam sistem database data pasien yang berupa tanggal lahir tidak dijadikan sebagai primary key. Maka dari itu disarankan untuk RSUD Tebet Jakarta untuk memperbaiki database yang berupa tanggal lahir pada tabel pasien menjadi primary key untuk menghindari terjadinya duplikasi data pasien di dalam sistem dan terjadinyaduplikasi data.
\end{abstract}

Kata Kunci : Sistem Pendaftaran, Sistem Informasi, Rawat Jalan.

\begin{abstract}
Outpatient registration is the initial service provided by the hospital to patients. Registration of outpatients at the Tebet Jakarta Hospital has been computerized with a website-based basis. The general purpose of this research is to review the information systemin the registration to be minimized. The research method used descriptive method is qualitative analysis. Data collection techniques by means of observation and interviews. From the results of the study, RSUD Tebet Jakarta has carried out computerized patient registration based on a website, using an application called the Hospital Information System (HIS) which was made by RSUD Tebet Jakarta and in collaboration with vendors. In the Hospital Information System (HIS) application, there are still obstacles that often arise, including searching for old patient data that does not carry a medical card, which is carried out in accordance with the rules of the Medical Record, namely only entering the patient's date of birth, but in Tebet Hospital there is still duplication of data patients when searching for patient data by date of birth because in the database system patient data in the form of date of birth is not used as the primary key. Therefore, it is recommended for RSUD Tebet Jakarta to improve the database in the form of date of birth for primary key patients to avoid duplication of patient data in the system and data duplication.
\end{abstract}

Keywords: Registration System, Information Systems, Outpatient 


\section{PENDAHULUAN}

Sistem Informasi Manajemen Rumah Sakit adalah sebuah sistem komputer yang memproses dan mengintegrasikan seluruh alur proses bisnis layanan kesehatan dalam bentuk jaringan koordinasi, pelaporan dan prosedur administrasi untuk memperoleh informasi secara cepat, tepat dan akurat. Saat ini Sistim Informasi Manajemen (SIM) berbasis komputer rumah sakit (SIMRS) merupakan sarana pendukung yang sangat penting, bahkan bisa dikatakan mutlak untuk mendukung pengelolaan operasional rumah sakit (Handiwidjojo, 2009).

Dengan perkembangan teknologi saat ini kebutuhan terhadap informasi sangat penting sehingga informasi harus dapat diakses kapan saja dan dimana saja dan tentu telahmengalami perkembangan yang pesat. Hampir semua kegiatan yang dilakukan oleh manusia pada jaman sekarang tidak luput dari campur tangannya sebuah teknologi berbasis Online dan tentunya sudah praktis serta terkomputerisasi. Dengan adanya kepraktisan dan komputerisasi ini dapat mempermudah dalam segala pekerjaan khususnya segala pendaftaran dan pengolahan datanya membutuhkan kecepatan, ketepatan atau kevalidan data. Salah satu yang dapatdirasakan oleh dampak dari kepraktisan dan terkomputerisasi ini yaitu di bidang pelayanan kesehatan dimana memerlukan teknologi informasi yang digunakan untuk proses penyimpanan data pasien.

Pemberian layanan dan tindakan dalam banyakhal akan mempengaruhi kondisi dan rasa nyaman bagi pasien. Semakin cepat akan semakin baik karenamenyangkut nyawa pasien. Semakin besar jasa layanan suatu rumah sakit, akan semakin kompleks pula jenis tindakan dan layanan yang harus diberikan yang kesemuanya harus tetap dalam satu koordinasi terpadu. Karena selain memberikan layanan, rumah sakit juga harus mengelola dana untuk membiayai operasionalnya. Melihat situasi tersebut, sudahsangatlah tepat jika rumah sakit menggunakan sisi kemajuan komputer, baik piranti lunak maupun perangkat kerasnya dalam upaya nya membantu penanganan manajemen yang sebelumnya dilakukan secara manual. Pengolahan data secara komputerisasi akan memudahkan dalam melaksanakan pekerjaan. Dengan adanya komputer yang dilengkapi program aplikasi yang menunjang akan memudahkan dalam menghasilkan informasi yang berkualitas. Penerapan teknologi informasi dalam bidang kesehatan yang dapat menghasilkan informasi yang cepat, akurat dan tepat akan meningkatkan mutu dan kualitas pelayanan kesehatan kepada pasien (Tumarta Arif, 2019).

Rumah sakit adalah suatu instansi yang dikelola baik oleh pemerintah daerah atau pusat, maupun pihak swasta, yang merupakan bagian dari organisasi umum. Undang-Undang RI No. 44 Tahun 2009 tentang rumah sakitdisebutkan bahwa Rumah Sakit adalah institusi pelayanan kesehatan yang menyelenggarakan pelayanan kesehatan perorangan secara paripurna yang menyediakan pelayanan rawat inap, rawat jalan, dan gawat darurat (Aguilera, 2009).

Rawat jalan tingkat pertama adalah pelayanan kesehatan perorangan yang bersifat non spesialistik yang dilaksanakan pada fasilitas kesehatan tingkat peratama untuk keperluan observasi,diagnosis,pengobatan,dan atau pelayanan kesehatan lainnya (Widjaja, 2015).

Berdasarkan hasil observasi awal yang dilakukan peneliti di Rumah Sakit Umum Daerah Tebet menghasilkan bahwa sistem pendaftaran di tempat pendaftaran pasien rawat jalan sudah terkomputerisasi dengan berbasis website. Rumah Sakit Umum Daerah Tebet memiliki Aplikasi Sistem Pendaftaran yang bernama Hospital Information System (HIS) yang digunakan sejak tahun 2017 setelah beberapa kali perbaikan. Aplikasi HIS dikembangkan oleh tim IT bersama sebuah vendor. Aplikasi HIS hanya dapat diakses oleh petugas pendaftaran rawat jalan. Sistem yang terdapat di aplikasi HIS masih memiliki beberapa kekurangan, diantaranya yaitu untuk pencarian data pasien lama yang tidak membawa kartu berobat yang dilakukan telah sesuai dengan aturan standar prosedur operasional pendaftran rawat jalan yaitu hanya memasukkan tanggal lahir, namun di RSUD Tebet Jakarta selatan masih terdapat duplikasi data pasien saat dilakukan pencarian data pasien berdasarkan tanggal lahir dan sistem yang terdapat di pendaftraan pasien rawat jalan sering eror/buffering. Berdasarkan permasalahan yang ditemukan di tempat pendaftaran pasien rawat jalan RSUD Tebet Jakarta Selatan aplikasi HIS masih perlu dikembangkan karena jika tidak 
dikembangkan akan mempengaruhi pelayanan Registrasi Pendaftaran di Rumah Sakit.

\section{METODE PENELITIAN}

Penelitian ini dilakuan melalui metode deskriptif yaitu dengan menjelaskan dan memberikan gambaran tentang hasil yang diperoleh secara lengkap tentang permasalahan dalam pendaftaran pasien rawat jalan yang sudah terkomputerisasi berbasis website di RSUD Tebet Jakarta Selatan. Pada penelitian ini tidak ada populasi dan sampel karena penulis menggunakan pendekatan kualitatif yaitu hanya informasi berdasarkan hasil observasi dan wawancara. Informan penelitian ini adalah tim IT yang berjumlah 4 petugas dan petugas pendaftaran rawat jalan yang berjumlah 2 petugas di RSUD Tebet Jakarta Selatan. Untuk memperoleh data dan informasi yang diperlukan dalam penelitian peneliti menggunakan dua cara untuk pengumpulan data yaitu dengan observasi dan wawancara.

\section{HASIL}

\section{Mengidentifikasi Standar Prosedur Operasional Pendaftaran Rawat Jalan di Rumah Sakit Umum Daerah Tebet}

Berdasarkan hasil penelitian di tempat pendaftaran pasien rawat jalan di rumah sakit daerah tebet Jakarta selatan memiliki SPO pendaftaran rawat jalan. Dari SPO tersebut petugas pendaftaran melakukan alur pendaftaran pasien sesuai dengan SPO yang berlaku. Petugas hanya melakukan pendaftaran sesuai dengan SPO yang ada. Peningkatan sebuah mutu pelayanan di Rumah Sakit Umum Daerah Tebet Jakarta Selatan sangat diperlukan sebagai penyelenggaraan suatu rangkaian kegiatan yang mencakup semua pelayanan kesehatan di Rumah Sakit Umum Daerah Tebet Jakarta Selatan disemua tingkatan administrasi yang dapat memberikan informasi kepada pengelola untuk proses manajemen yang berhubungan dengan pengumpulan data, penyajian informasi, analisa pelayanan kesehatan dan pengolahan data. Namun, untuk SPO dari sistem masih belum tersedia berdasarkan hasil wawancara dengan petugas IT peneliti tidak menemukan Standar Prosedur Operasional dari sistem HIS, dikarenakan pihak dari rumah sakit pada saat menerima sistem dari vendor tidak memahami bahwa spo tersebut sangat diperlukan. Oleh karena itu pihak rumah sakit hingga saat ini tidak mempunyai SPO dari sistem tersebut dan pihak rumah sakit menjalankan sistem his berdasarkan training/pelatihan.

\section{Mengidentifikasi Sistem Pendaftaran Pasien Rawat Jalan di Dalam Sistem Berbasis Komputerisasi}

Berdasarkan hasil penelitian di tempat pendaftaran pasien yaitu sistem pendaftaran rawat jalan di RSUD Tebet sudah terkomputerisasi berbasis web site. Pendaftaran pasien rawat jalan di rumah sakit memiliki aplikasi yang bernama Hospital Information System yang sudah digunakan sejak tahun 2017.

\section{Gambaran Sistem Informasi Pendaftaran Pasien Rawat Jalan di Rumah Sakit Umum Daerah Tebet Jakarta Selatan}

\section{Tampilan menu log in pada aplikasi HIS}

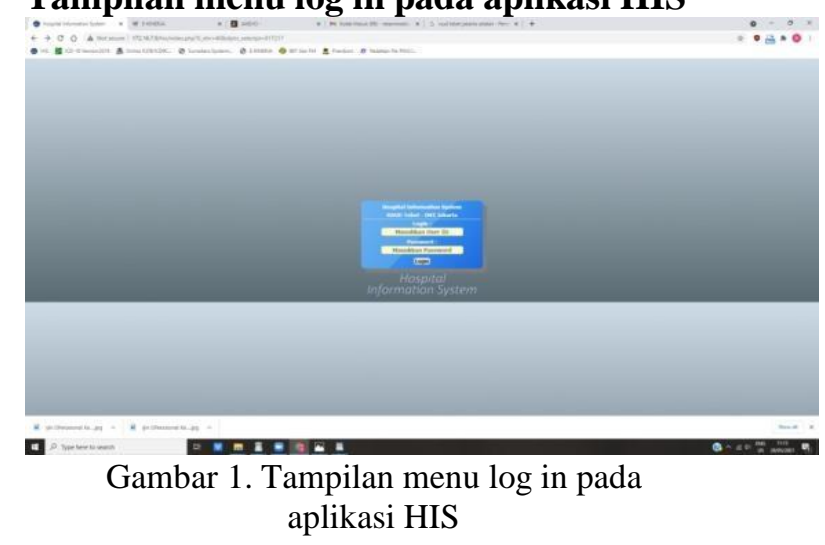

Pada Dashboard ini user melakukan log in untuk dapat masuk kedalam sistem HIS. Untuk dapat mengakses harus login dengan menyertakan userID dan password dari masingmasing user diantara user tersebut tidak saling mengetahui password untuk log in, dikarenakan data pasien yang diinput berbeda-beda. 


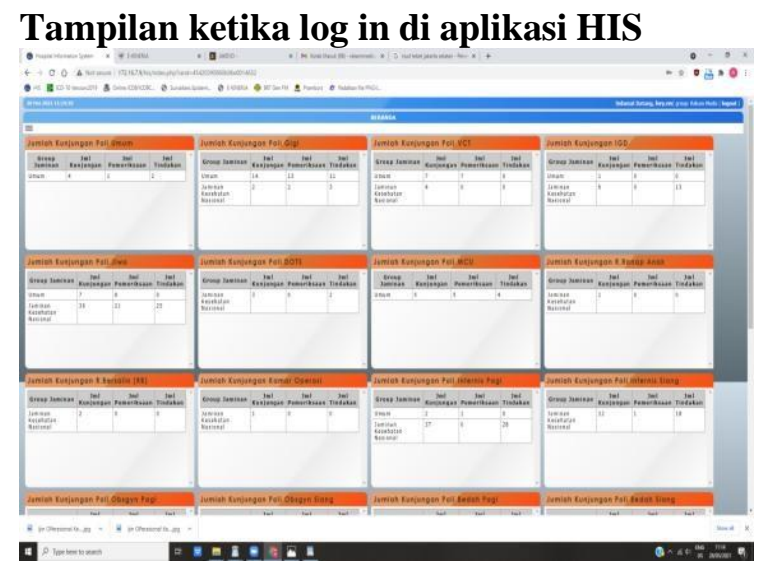

Gambar 2. Tampilan ketika log in di aplikasi HIS

Setelah user melakukan log in dengan menggunakan user ID dan password masingmasing, terdapat dashboard yang berisi beranda jumlah kunjungan poliklinik.

\section{Tampilan ketika akan mendaftarkanPasien}

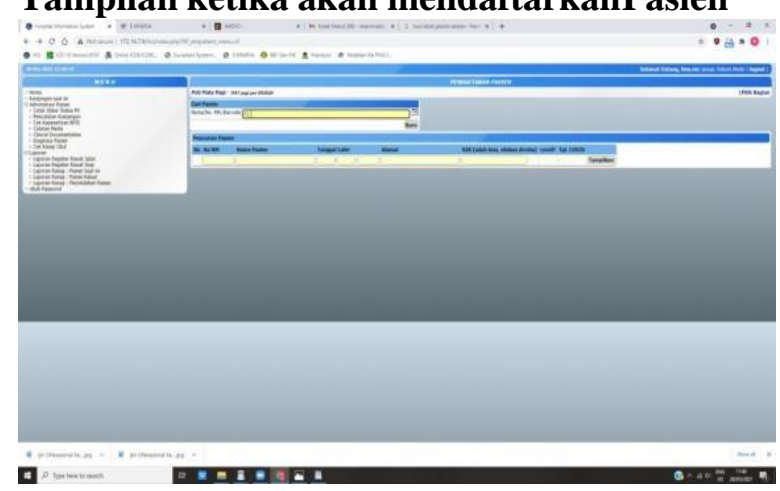

Gambar 3. Tampilan ketika akan mendaftarkan pasien

Pada dashboard ini terdapat perbedaan untuk melakukan registrasi pendaftaran pasien , yaitu jika pasien tersebut pasien lama tinggal memasukkan nomor Rekam Medis pasien, tetapi jika pasien tersebut pasien baru petugas harus mengisi data pasien dengan klik tombol pasien baru dibawah kolom pencarian nomor rekam medis.

\section{Tampilan pendaftaran Pasien Yang Wajib di}

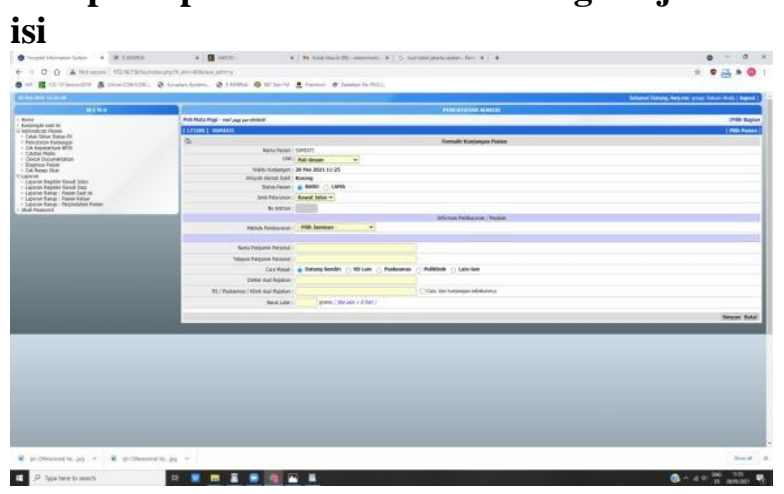

Gambar 4. Tampilan pendaftaran Pasien Yang Wajib di isi

Terdapat menu yang wajib diisi oleh petugas pendaftaran, diantaranya yaitu nomor rekam medis, NIK, nama lengkap pasien, tanggal lahir pasien, jenis kelamin, nama orang tua pasien, dan alamat, setelah semuanya terisi petugas mengklik tombol di bagian bawah dashboard untuk menyimpan datadan mencetak kartu pasien dan stiker RM.

\section{Tampilan setelah selesai mengisi pendaftaran} pasien

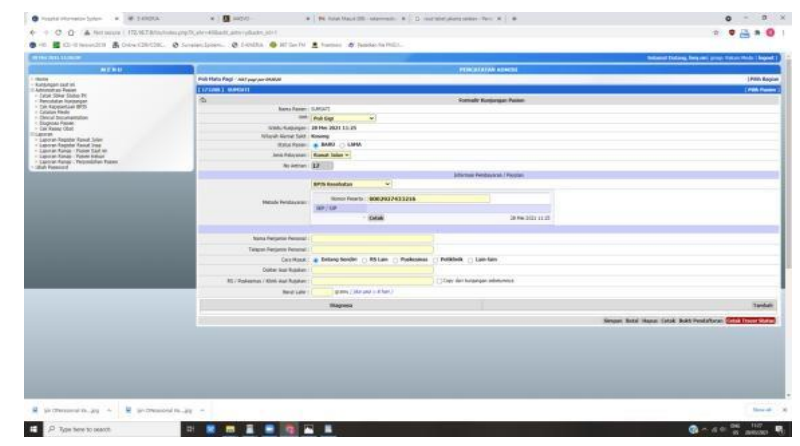

Gambar 5. Tampilan setelah selesai mengisi pendaftaran pasien

Pada dashboard ini berisi pencatatan admisi seperti formulir kunjungan pasien dan informasi pembayaran/payplan. Pada formulir kunjungan terdapat pilihan poliklinik, waktu kunjungan pasien dan jenis pelayanan pasien. Di payplan terdapat pilihan metode pembayaran. 


\section{Tampilan Tahapan Untuk Cetak Tracer Status}

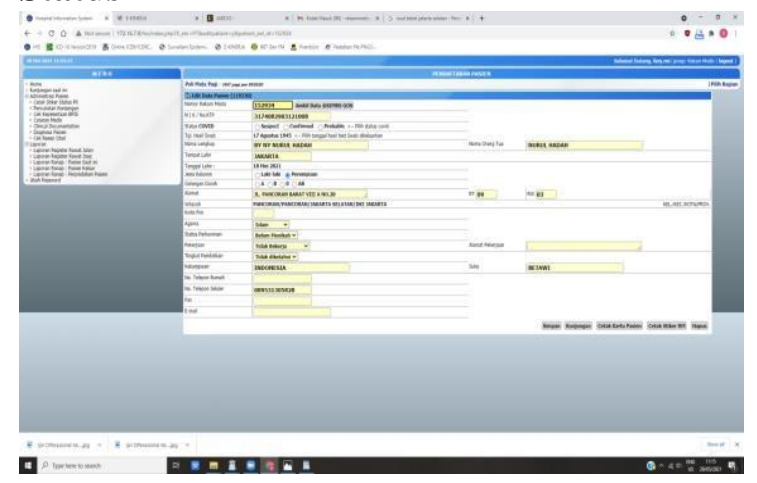

Gambar 6. Tampilan Tahapan Untuk Cetak Tracer Status

Setelah semua rangkaian pendaftaran telah diisi oleh petugas selanjutnya petugas mengklik tombol berwarna merah yang terdapat tulisan cetak tracer status untuk mencetak tracer pasien.

Dari hasil langkah-langkah penggunakan aplikasi HIS tersebut dapat disimpulkan bahwa tampilan yang terdapat pada aplikasi HIS tersebut sudah user friendly. Petugas pendaftraan sudah dapat memahami langkah-langkah dalam melakukan penerapan aplikasi pendaftaran pasien rawat jalan. Diantara petugas pendaftaran tidak saling mengetahui username dan password petugas pendaftaran pasien lain untuk login ke aplikasi HIS, namun pada saat petugas pendaftaran akan mendaftarkan pasien rawat jalan terdapat kendala yaitu ketika petugas pendaftaran mendapatkan pasien lama yang tidakmembawa kartu berobat, petugas mencari data pasien lama tersebut dengan tanggal lahir pasien, tetapi data pasien tersebut tidak dapat ditemukan sehingga terjadinya duplikasi nomor rekam medis dan jaringan yang terdapat pada sistem pendaftaran tersebut terkadang mengalami gangguan/buffering sehingga menyebabkan pendaftaran pasien menjadi terhambat dan terkadang sering terjadi human error dari petugas karena terlalu banyaknya pasien sehingga petugas bisa salah mengklik pada saat pendaftaran.

\section{Mengidentifikasi Struktur Database yang terdapat pada Sistem Pendaftaran Pasien Rawat Jalan}

Berdasarkan hasil wawancara dengan tim IT diRSUD Tebet Jakarta selatan, menghasilkan bahwa DataBase yang dibuat sudah sesuai dengan kebijakan yang ada. DataBase tersebut memiliki 5 tabel, yaitu:

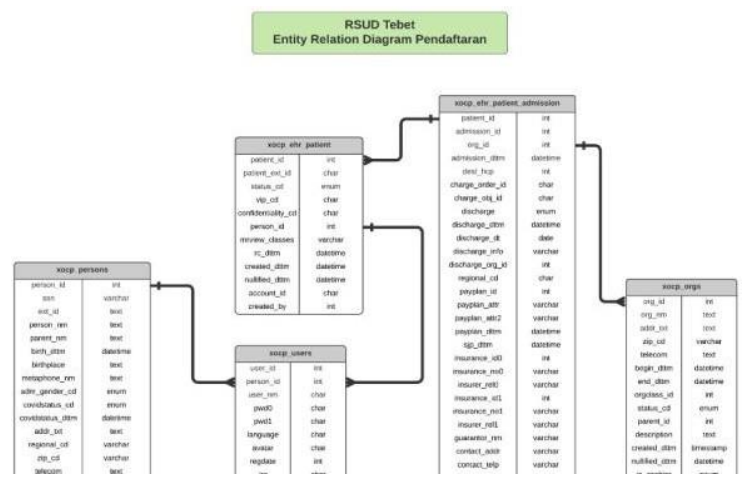

Gambar 7. Sturktur Database Sistem pendaftaran Rawat Jalan RSUD Tebet

\section{Tabel Pasien (Pasien Lama)}

Table Pasien tersebut adalah data dari seluruh pasien yang datang berkunjung untuk berobat di Rumah Sakit Umum Daerah Tebet Jakarta selatan.

\section{Tabel user (Petugas Pendaftaran)}

Tebel tersebut digunakan untuk mendata user dari masing-masing pelayanan yang terdapat di Rumah Sakit Umum Daerah Tebet Jakarta selatan.

\section{Tabel Person (Pasien Baru)}

Tabel tersebut digunakan untuk mengetahui Identitas daripada pasien yang akan berobat diawal pendaftaran

\section{Tabel Orgs (Poliklinik)}

Tabel tersebut digunakan untuk mendata kode poliklinik dan nama poliklinik.

\section{Tabel Admission Pasien (Penerimaan Pasien) \\ Tabel tersebut digunakan untuk Mendata segala kegiatan pasien (jenis penyakit, dokter, pembayaran, dll) selama berobat di RSUD Tebet Jakarta Selatan dari awal pasien mendaftar sampai pasien selesai berobat.}




\section{PEMBAHASAN}

\section{Mengidentifikasi Standar Prosedur Operasional (SPO) di Tempat Pendaftaran Pasien Rawat Jalan Rumah Sakit Umum Daerah Tebet Jakarta Selatan}

Berdasarkan hasil penelitian di Rumah Sakit Umum Daerah Tebet Jakarta Selatan di temukan bahwa Rumah Sakit Umum Daerah Tebet sudah memiliki Standar Prosedur Operasional terkait pendaftaran pasien rawat jalan. Dengan adanya Standar Prosedur Rumah Sakit dan meningkatan kualitas pelayanan yang ada pada Rumah Sakit menjadi lebih baik serta petugas pendaftaran rawat jalan memiliki acuan untuk menjalankan pekerjaannya sesuai dengan Standar Prosedur Operasional. Namun untuk Standar prosedur Operasional sistem HIS masih belum tersedia dikarenakan pihak dari rumah sakit pada saat menerima sistem dari vendor tidak memahami bahwa SPO tersebut sangat diperlukan. Oleh karena itu pihak rumah sakit hingga saat ini tidak mempunyai SPO dari sistem tersebut dan pihak rumah sakit menjalankan sistem his berdasarkan training/pelatihan.

SPO adalah suatu instruksi/langkahlangkah yang dibakukan untuk menyelesaikan proses kerja rutin tertentu, atau langkah yang benar dan terbaik berdasarkan konsensus bersama dalam melaksanakan berbagai kegiatan dan fungsi pelayanan yang dibuat oleh fasilitas pelayanan kesehatan berdasarkan standarprofesi (Kemenkes RI, 2010)

Pelaksanaan pendaftaran pasien rawat jalan sudah sesuai dengan Standar Prosedur Operasional jika pasien tersebut adalah pasien lama petugas hanya meminta kartu berobat pasien. Tetapi jika pasien tersebut tidak membawa kartu berobat, maka pasien hanya menyebutkan tanggal lahir kemudian petugas mendaftarakan pasien sesuai dengan poliklinik yang hendak dituju, tetapi jika pasien baru maka harus mengisi formulir pendaftaran terlebih dahulu sesuai dengan KTP kemudian petugas memasukkan data pasien sesuai dengan sistem aplikasi dan dibuatkan kartu berobat lalu mendaftarkan pasien sesuai dengan poliklinik yang dituju. Petugas pendaftaran rawat jalan di RSUD Tebet sudah bekerja sesuai dengan standar prosedur operasional yang telah ditetapkan, namun jika terdapat pasien lama yang tidak membawa kartu berobat petugas mencari dengan tanggal lahir pasien tetapi terkadang data pasien lama tidak muncul atau tidak terdeteksi dan petugasmembuat nomor rekam medis baru, dari hal tersebut akan berdampak pada duplikasi nomor rekam medis pasien. Seharusnya jika petugas mendapatkan pasien lama yang tidak membawa kartu berobat maka petugas tersebut langsung mencari KIUP (kartu indeks utama pasien) untuk mencegah agar tidak terjadi duplikasi nomor rekam medis tetapi dikarenakan petugas pendaftaran tersebut bukan dari latar belakang pendidikan rekam medis, petugas pendaftaran rawat jalan tidak mengetahui akan KIUP tersebut.

Menurut Robetty, dalam mempermudah pencarian berkas rekam medis maka diperlukan suatu alat yang dapat membantu petugas untuk penghematan waktu dalam pencarian berkas. Alat tersebut adalah KIUP atau Kartu Indeks Utama Pasien, KIUP adalah suatu kartu katalog yang berisikan nama semua penderita yang pernah berobat ke rumah sakit. Informasi yang terkandung dalam KIUP merupakan kunci untuk menemukan berkas rekam medis pasien. Dengan tidak adanya KIUP ini maka petugas akan kesulitan dalam melayani pasien yang tidak membawa kartu berobat, dan petugas memberi nomor baru kepada pasien, oleh karena itu terjadinya duplikasi berkas rekam medis (Robetty, 2016).

\section{Mengidentifikiasi Sistem Pendaftaran Pasien Rawat Jalan di Rumah Sakit Umum Daerah Tebet Jakarta Selatan}

Berdasarkan hasil wawancara dengan petugas pendaftaran rawat jalan RSUD Tebet Jakarta Selatan tempat pendaftaran pasien rawat jalan sudah terkomputerisasi berbasis website dan mempunyai aplikasi yang bernama Hospital Information System (HIS). Dengan pendaftaran yang sudah terkomputerisasi memudahkan petugas dalam melakukan pendaftaran rawat jalan. Namun aplikasi HIS ketika akan mencari data pasien lama yang tidak membawa kartu berobat sistem tersebut tidak dapat mencari menggunakan tanggal lahir pasien, sehingga terjadinya duplikasi nomor Rekam Medis. Alangkah baiknya jika Rumah Sakit dapat memperbaiki sistem yang tidak dapat mencari data pasien lama dengan hanya menggunakan tanggal lahir, dan mengevaluasi serta memperbaiki agar sistem yang terdapat di 
pendaftaran pasien rawat jalan tidak terjadi eror/buffering.

Gurbanova mengemukakan bahwa di dalam sistem informasi manajemen perlu memperhatikan perubahan-perubahan yang terjadi, direncanakan, dan dikendalikan secara sistematis. Pelayanan di tempat pendaftaran pasien rawat jalan (TPPRJ) merupakan pelayanan yang bersifat administrative bukan pelayanan medis namun kesinambungan informasi medis dan kerahasiaannya harus tetap terjaga serta informasi yang dihasilkan juga harus akurat, tepat waktu, dan relevan dalam mengambil sebuah keputusan (Gurbanova, 2016).

\section{Mengidentifikasi Struktur Database Pendaftaran Pasien Rawat Jalan}

Berdasarkan permasalahan yang terjadi di tempat pendaftaran pasien rawat jalan, ketika sistem tersebut mencari data pasien lama dengan menggunakan tanggal lahir, data pasien tersebut tidak ditemukan. Hal ini dikarenakan tanggal lahir pasien di dalam sistem pendaftaran rawat jalan tidak sebagai Primary Key, dimana Primary Key di dalam sistem adalah ID Pasien. Seharusnya pada saat membuat database tanggal lahir dibuat sebagai primary key nya agar ketika sistem tersebut digunakan petugas pendaftaran dapat menemukan data pasien lama yang tidak membawa kartu berobat dengan menggunakan tanggal lahir pasien, karena tanggal lahir pasien adalah data yang mudah diingat dan data akurat ketika pasien tidak membawa kartu berobat tersebut, sehingga tidak terjadi duplikasi data pasien.

\section{SIMPULAN}

Berdasarkan hasil penelitian dan pembahasan diatas, maka dapat disimpulkan bahwa, RSUD Tebet sudah memiliki SPO pendaftaran pasien rawat jalan melalui petugas pendaftaran, kegiatan pelaksanaannya sudah sesuai dengan Standar Prosedur Operasional yang ada tetapi RSUD Tebet belum memiliki SPO sistem pendaftaran pasien rawat jalan dikarenakan sistem dibuat oleh vendor dan pada saat rumah sakit menerima sistem tersebut pihak dari rumah sakit tidak memahami SPO dari sistem tersebut sangat penting dan petugas menjalankan sistem berdasarkan dengan pelatihan/training. Tempat pendaftaran pasien rawat jalan di RSUD Tebet Jakarta Selatan sudah terkomputerisasi dengan berbasis website. Namun masih terdapat kendala diantaranya yaitu system pendaftaran rawat jalan tidak dapat menemukan data pasien lama dengan tanggal lahir ketika pasien tidak membawa kartu berobat sehingga petugas menginput ulang data pasien yang mengakibatkan terjadinya duplikasi data pasien didalam sistem. Database yang dibuat untuk sistem pendaftaran rawat jalan terdapat primary key tetapi untuk data pasien yang berupa tanggal lahir tidak menjadi primary key pada database tersebut, sehingga pada saat pasien tidak membawa kartu berobat dan petugas menginput data pasien dengan menggunakan tanggal lahir maka tidak ditemukan data pasiennya.

Dalam rangka meningkatkan pelayanan di RSUD Tebet Jakarta Selatan, peneliti memberikan beberapa saran yaitu, Sebaiknya prosedur yang telah dilaksanakan tetap di pertahankan dan sebaiknya segera dibuat Standar Prosedur Operasional sistemnya agar dapat memperbaiki pelayanan di rumah sakit. Dan di era modern seperti saat ini, sebaiknya tempat pendaftaran pasien tetap menerapkan sistem pendaftaran pasien secara terkomputerisasi karena akan mempermudah dalam pencatatan pasien dan pelaporan. Sebaiknya di dalam database data pasien yang berupa tanggal lahir pasien di buat sebagai Primary Key pada tabel pasien, sehingga pada saat pasien tidak membawa kartu berobat pasien tersebut hanya memberi tahu tanggal lahir pasien kepada petugas dan petugas dapat menemukan data pasien tersebut dengan tanggal lahir. Hal ini untuk menghindari terjadinya duplikasi data pasien.

\section{DAFTAR RUJUKAN}

Aguilera, M. (2009). UU RI NO.44 THN 2009. Uu Ri No.44 Thn 2009, 2(5), 255.

Gurbanova, A. (2016). Sistem Informasi Pendaftaranpasien Di Klinik Mitra Kita Semarang. Skripsi, 1-17.

Handiwidjojo, W. (2009). Makalah Sistem Informasi Manajemen Rumah Sakit. EKSIS, 02(02), 32-38. Retrieved from https://rusdinncuhi.wordpress.com/2013/07 /04/makalah-sistem-informasi-manajemenrumah-sakit/ 
8 | Indonesian Journal of Health Information Management (IJHIM), Vol. 2 No. 1 (2022),

Kemenkes RI. (2010). Peraturan Menteri Kesehatan Republik Indonesia Nomor 1438/MENKES/IX/2010 Tentang Standar Pelayanan Kedokteran. Peraturan Menteri Kesehatan, 132(464), 140-145.

Robetty, R. (2016). Perancangan KIUP Elektronik dengan Menggunakan Program Microsoft Visual Basic 6.0 di Rumah Sakit Bangkatan Binjai Tahun 2015. Jurnal Ilmiah Perekam Dan Informasi Kesehatan Imelda, 1(1), 1-5. Retrieved from https://media.neliti.com/media/publications /299150-perancangan-kiup-elektronikdengan-mengg-01cfbacf.pdf

Tumarta Arif, Y. W. (2019). Komputerisasi Pendaftaran Pasien Rawat Jalan Berbasis Web Di Praktek Dokter. Jurnal Rekam Medis Dan Informasi Kesehatan, 2(1), 1. https://doi.org/10.31983/jrmik.v2i1.4088

Widjaja, L. (2015). Manajemen informasi kesehatan. 